\title{
ERRATUM
}

The Journal of Microbiology (2012) Vol. 50, No. 1, pp. 149-154

Copyright (c) 2012, The Microbiological Society of Korea

\section{Neutralization Potential of the Plasma of HIV-1 Infected Indian Patients in the Context of Anti-V3 Antibody Content and Antiretroviral Theraphy}

\author{
Alok Kumar Choudhary ${ }^{1 \dagger}$, Raiees Andrabi ${ }^{1 \dagger}$, Somi Sankaran Prakash ${ }^{1 \dagger}$, Rajesh Kumar ${ }^{1}$, \\ Shubhasree Dutta Choudhury ${ }^{1}$, Naveet Wig ${ }^{2}$, Ashutosh Biswas ${ }^{2}$, Anjali Hazarika ${ }^{3}$, and Kalpana Luthra ${ }^{1 \star}$ \\ ${ }^{1}$ Department of Biochemistry, ${ }^{2}$ Department of Medicine, ${ }^{3}$ Department of Blood Bank, CN Centre, \\ All India Institute of Medical Sciences, 110029, New Delhi, India
}

In the article by Choudhary et al. that appears in the Journal of Microbiology 2012; 50, 149-154. Page 149, on journal title 'Theraphy' should read 'Therapy'. 